\title{
An Original Mid-Nineteenth Century Scientific Instrument in Italy: Vincenzo Vignola's Induction Coil
}

\author{
Roberto Mantovani \\ Department of Basic Sciences and Foundations, Physics Laboratory: Urbino Museum of Science and Technology, \\ University of Urbino Carlo Bo, Urbino, Italy \\ Email: roberto.mantovani@uniurb.it
}

Received 26 February 2015; accepted 9 April 2015; published 7 May 2015

Copyright (C) 2015 by author and Scientific Research Publishing Inc.

This work is licensed under the Creative Commons Attribution International License (CC BY). http://creativecommons.org/licenses/by/4.0/

(c) (i) Open Access

\begin{abstract}
It is well known that the induction coil was invented in the mid-1830s, but its most significant improvements were made between the late 1830s and 1851. During these years a lot of research was aimed at improving the functionality and effectiveness of the device. In Italy one of the very first attempts at improvement was made first by an instrument maker from Milan, Carlo Dell'Acqua, and secondly, by a priest from Verona, Vincenzo Vignola. In 1851, Vignola was awarded the gold medal from the Academy of Agriculture, Arts and Commerce of Verona for having introduced important and useful changes to the Callan electromotor. This event opened up the discovery of a number of very interesting, unpublished hand-written documents, as well as the discovery of the device itself, provided with an almost unique self-acting commutator-interrupter system. Today this apparatus is preserved at the Physics Museum "Antonio Maria Traversi" in Venice.
\end{abstract}

\section{Keywords}

Induction Coil, Carlo Dell'Acqua, Vincenzo Vignola, Paolo Vignola, Giovanni Battista Battocchi, Nicholas Joseph Callan, Giuseppe Pederzolli, Gianalessandro Majocchi, Heinrich Daniel Ruhmkorff, Circuit Breaker, Commutator

\section{Introduction}

Many years ago, while visiting a historical collection of scientific instruments in Venice, I was impressed by an induction coil which featured a particular interrupter unlike any other that was known to or described in physics textbooks from the 19th century. I began to study it and, thanks to some historical information appearing on the 
instrument itself, I managed to identify a number of unpublished manuscripts which helped me understand the interrupter's functioning principle and to trace its story. The present paper reconstitutes the history of that peculiar scientific device and at the same time provides some insight into how the induction coil was introduced and received in Italy. As a teaching and research instrument, the induction coil was widely used in the physics cabinets of schools, universities and research centers throughout the second half of the nineteenth century. When it first came out, the instrument made its entrance as an innovative transformer of high voltage electrical impulses. More precisely, the instrument, powered by an inlet low-voltage direct current, allowed for the generation, in a spark gap, of pulsating currents or discharges of high electromotive force, in some cases equal to hundreds of thousands of volts. Its history is very well known and has largely been reconstructed (Fleming, 1892; Payen, 1965; Shiers, 1971; Hackmann, 1989), especially as concerns the creation of the early models that appeared, independently of each other, in the Unites States (Page, 1867; Post, 1976; Greenslade, 2013) and in Europe.

\section{Notes on the History of the Induction Coil}

The discovery in 1831 of Faraday's electromagnetic induction made available an entirely new technology that, on its turn, would prove instrumental, in the years to come, to the design of new and increasingly effective magneto electric generators and induction coils. The latter began to be built and closely studied in the mid-1830s. In 1835, the American scientist Joseph Henry (1797-1878), while studying the passage of direct current through a coil, invented the first auto-transformer. In this device, certain portions of the same coil simultaneously acted as primary and secondary windings (Hackmann, 1998: p. 328). Henry's research was carried on in his home country in a more practical manner by the electrical scientist and inventor Charles Grafton Page (1812-1868) and by the well-known manufacturer and dealer of scientific instruments in Boston, Daniel Davis (1813-1887). In the United Kingdom, both the Irish priest Nicholas Joseph Callan (1799-1864) and the Englishman William Sturgeon (1783-1850) contributed to the development of the first induction coil prototypes. Reverend Callan, a professor of Natural Philosophy at Maynooth College (a seminary in Southern Ireland), had the merit, in 1836, to design the first induction coil prototype, that would go on to become the most successful of all. The Callan device consisted of two windings of well insulated copper wire: the primary winding was powered by direct current by a single galvanic cell and consisted of a small number of turns of thick wire around a soft iron core; the secondary winding, which was laid out coaxially on top of the primary, consisted of an unconnected coil with a greater number of turns of fine wire. In order to create the flux variations in the magnetic field necessary for the induction of high voltages in the secondary circuit, Callan used a mercury interrupter, called "repeater", which would repeatedly and rapidly interrupt the current in the primary winding, at a rate of more than fifty interruptions per second. In the summer of 1837, Callan sent a small prototype of his induction coil to William Sturgeon, an English electrical engineer and inventor who had founded, the year before, a monthly periodical titled Annals of Electricity, Magnetism and Chemistry; this was an important magazine of its time, the first one in England to be entirely dedicated to the study of electricity. In 1837 Callan published a description of his "repeater” in Sturgeon's Annals (Callan, 1836) and, from that year and until roughly 1850, the magazine featured materials on a number of improvements brought to the new instrument, including the important one contributed by George Henry Bachhoffner (1810-1879). The instrument reached its definitive structure in 1851 thanks to the German mechanical engineer Heinrich Daniel Ruhmkorff (1803-1877), who worked in Paris as a famous designer and manufacturer of teaching and laboratory scientific instruments. As a matter of fact, Ruhmkorff, building upon the incremental improvements from previous attempts by other scientists who had aimed at improving the device, brought a number of crucial changes, enhancing it to such an extent that it subsequently began to be known simply as the Ruhmkorff coil. The device was successfully shown during the great Paris Universal Exhibition in 1855 and, from then on, it started being sold regularly and became very popular. In the beginning, its main application was medical, as the new faradaic electricity was believed to have healing effects, especially as concerns the neuromuscular system (Rowbottom \& Susskind, 1984). Thus, a great number of pocket electromedical induction machines were invented; these were mostly wooden boxes of rather small size and weight, basically equipped with small cells, rheophores, electrodes and induction coils that were supposed to yield substantial therapeutic benefits in various diseases, based on the practice of electric shocks. Towards the end of the 19th century, the induction coil also became known as an irreplaceable laboratory instrument for physicists, either for teaching purposes_-for example, in order to demonstrate electromagnetic induction-, or to power high vacuum discharge tubes, arc lighting, X-ray tubes and spark-gap radio transmitters. 


\section{The First Induction Coils in Italy}

If we leave out the sparking magnet designed by the Italian physicists Leopoldo Nobili (1785-1835) and Vincenzo Antinori (1792-1865) in 1832, the first machines generating currents induced by permanent magnets started to come into use in the laboratories of the Italian peninsula around the year 1836. Their diffusion was mostly driven by the news appearing in foreign scientific magazines and sometimes picked up and circulated by the Italian journals; such diffusion was also spurred by the purchase of such machines from abroad, especially from England ${ }^{1}$. Just like magneto electric machines, also the induction coil was introduced in Italy a few years later, around the year 1840. The most important information on this matter is provided by Majocchi ${ }^{2}$, who also claimed to be the first to introduce the machine in Italy. In one of his most successful physics texts, Majocchi states:

This machine, which can function as a powerful electromotor in many circumstances, was born shortly after the discovery of induced currents and we were the first to introduce it in Italy, under the name of induction electro-magnetic motor (Majocchi, 1853, Vol II: p. 803) ${ }^{3}$.

Majocchi, who at that time was teaching physics at the Imperial Regio Liceo of San Alessandro in Milan, had found the information on the new instrument in Sturgeon's Annals of Electricity and it is likely he discussed the instrument's operation with Carlo Dell'Acqua ${ }^{4}$, who was his machinist and mechanic assistant at San Alessandro high school. The weak point of the English instrument turned out to be the mechanical interrupter made by a toothed zinc disc with flexible thin brass strip contact that was activated manually by means of a hand-cranked. The possibility of rendering more effective the interruption system of the primary winding did not go unnoticed by Dell'Acqua; in the early 1840 Dell'Acqua, on the basis of a change ${ }^{5}$ made to Ritchie's ${ }^{6}$ electromagnetic motor, came up with an ingenious automatic rotating mercury interrupter, which was to replace the manually activated one. The new model (see the drawing in Figure 1), described in some texts of the time as an induction coil with a rotating voltaic magnet, was the first autochthonous example of induction coil originated in Italy, after the induction electromotor had been imported from England. This coil was sold by Dell'Acqua and it circulated mostly in Northern Italy from 1841 to 1851.

\section{Vincenzo Vignola’s Induction Coil}

The circulation of the rotating voltaic magnet device fostered the diffusion and the use of the induction coil in Italy. However, it soon became obvious that Dell'Acqua's instrument presented various defects, especially when used for long periods of time. The coil was studied with particular attention by Vincenzo Vignola ${ }^{7}$ from Verona, who would then enter the order of the Sacred Stigmata in 1856. He found that the part of the coil relating to the interrupter, did not work properly, so after several attempts, he designed a new induction coil. Fortunately, a physical

\footnotetext{
${ }^{1}$ The machines thus purchased were often the source of technical analyses and vivid scientific discussions between the numerous and competent machinists and custodians of scientific instruments who worked in close collaboration with local scientists within schools and seminaries throughout the Italian peninsula. They often served as models for the reconstruction of new machines or for making more effective functional changes.

${ }^{2}$ Giovanni Alessandro or Gianalessandro Majocchi (1795-1854), an Italian physicist and engineer, obtained his university degree in Pavia in 1816 and in 1819 he started teaching mathematics and german language at Sondrio High-School; in 1826, he began to teach physics at the High-School of Mantua. From 1830 to 1848 he was professor of physics and mechanics at the High-School of San Alessandro in Milan. After the Italian insurrections of 1848, Majocchi took refuge in Turin, where, in the University, worked as an assistant of the physics professorship and at San Carlo Technical Institute as a teacher of "People’s physics” on evening classes.

${ }^{3} \mathrm{At}$ the end of the volume, the folding engraved plate No 20, shows an image of the instrument (fig. 342).

${ }^{4}$ Dell'Acqua was one of the most important scientific instrument maker in nineteenth-century Italy. Until 1859, he was a mechanical preparer or "machinist" at the physics cabinet of the Royal High School of Sant'Alessandro in Milan and, later on, he worked as a "mechanical engineer" at the Royal Astronomical Observatory in Brera. One of his catalogues, dated 1863, price-lists a rich and wide variety of scientific instruments including no less than 857 entries, all manufactured for research and teaching purpose for the benefit of the physics cabinets.

${ }^{5}$ This change consisted in eliminating the system of polar expansions between which a small electromagnet could rotate into a U-shaped vertical permanent magnet.

${ }^{6}$ William Ritchie (1790-1837), a physicist and astronomer of Scottish origin, was a rector of the Royal Academy of Tain (Scotland); he then went on to Paris, to study under Gay Lussac and Biot. In 1829 he moved to London, where he first taught Natural and Experimental Philosophy at the Royal Institution and then, from 1832, NaturalPhilosophy and Astronomy at the University.

${ }^{7}$ The last but one of 6 children (5 brothers and one sister), Vincenzo Vignola (Verona 1821, Parma 1899) studied at Verona high school. In 1840, following the footsteps of his 4 older brothers, he enrolled in Verona's Episcopal seminary and was ordained in 1844. Like his brother Paolo, Vincenzo distinguished himself in physics and mathematics, first teaching both subjects at the Stigmatine high school of Verona, from 1862 to 1866, and then at the Stigmatine high school of Villazzano (a hamlet of Trento), from 1866 to 1874 (Gurisatti, 1916: pp. 32-57).
} 


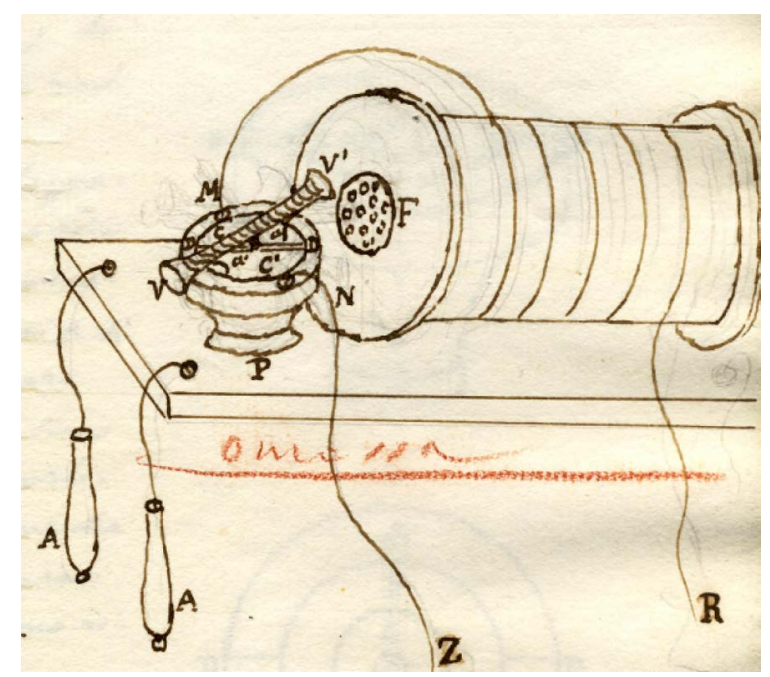

Figure 1. The original drawing of the induction coil with a rotating voltaic magnet owned by Spandri and found in Paolo Vignola's manuscript memoir. By courtesy of “Accademia di Agricoltura, Scienze e Lettere” in Verona.

trace remains of this second device, which was also the first to be entirely Italian in terms of both design and construction: the trace is the induction coil itself ${ }^{8}$, which is now preserved in the Antonio Maria Traversi Physics Museum $^{9}$ of Venice (see Figure 2). Its story came to light thanks to the discovery of a number of documents ${ }^{10}$, some handwritten and some printed, as well as through the analysis of the device itself, which reveals precious information in some of its parts. Namely, the device has two elegantly framed silver oval plates fixed on the high rims of the wooden frame that supports the secondary winding. The two surfaces of each oval are presented with a couple of inscriptions as follows:

\footnotetext{
"Macchina d'induzione magnetoelettrica [Induction magneto-electric machine]"; "Volante e Commutatore

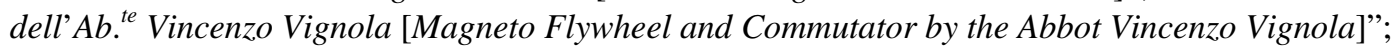

"Giov. Batta. Battocchi di Verona migliorò amplificò e costrusse [Improved, Increased its power and Built by Giov. Batta. Battocchi of Verona]; "Premiata con medaglia d'oro e d'argento dall'I.R. Istit. Veneto e dall'Accademia di Verona [Awarded the gold and silver medals by the Imperial Royal Veneto Institute and by the Academy of Verona]".
}

The inscriptions ascribe the mercury interrupter-commutator system design to Abbot Vignola and the construction of the machine to the Verona-based manufacturer Giovanni Battista Battocchi ${ }^{11}$; moreover, the inscriptions show that the device received two awards ${ }^{12}$. Particularly, the medal awarded in 1851 by the Academy of

\footnotetext{
${ }^{8}$ The device bears the inventory number 326 (inv. 1870). The instrument was purchased in 1852; it became part of the heritage of the Physics Cabinet of the I.R. High School of Santa Caterina ofVenice thanks to an ordinance issued by the Lieutenancy of Austria (No. 5333, March 12) which, for that year, had allocated an extraordinary endowment for the reorganization of the institute's science cabinets (Zambra, 1852: p. 18).

${ }^{9}$ The Museum is currently located inside the Venetian high school "Marco Foscarini”, founded in 1807, one of the oldestpublic schools in Italy. The museum, which has a permanent exhibition open to the public, owns almost five hundred antique scientific instruments from the physics cabinet of the Santa Caterina Boarding School, which was the old name of the institution, renamed after the unification of Italy in honor of the Venetian Doge Marco Foscarini. The Museum is also available on the Web at: http://museo.liceofoscarini.it/index_uk.html.

${ }^{10}$ One of these documents is of fundamental importance, as we will see further on, namely a manuscript written in 1852 by Paolo Vignola, discovered in the archives of the Accademia di Agricoltura, Scienze e Lettere in Verona.

${ }^{11}$ Giovanni Battista Battocchi, who was active until around 1890, mainly built electric and telegraphic instruments. He participated and won prizes in a number of national and international exhibitions, among them those of Venice, Padua, Treviso, Paris (1867 and 1878), Vienna (1873), and Milan (1881). In the 1870s, Battocchi was the trusted mechanic of the Academy of Agriculture, Arts and Commerce (currently named the Accademia di Agricoltura, Scienze e Lettere of Verona) which awarded him two gold medals and two silver medals for the outstanding quality of his instruments. The related documents and instruments found, not only highlightthe precision and elegance of his apparatus, but also the very reasonable costs of his business.

${ }^{12}$ In the Verona Academy public session of May 22, 1851, a gold medal was bestowed upon Abbot Vincenzo Vignola "for useful changes of Callan's electromotor that generate much larger effects than the ordinary". The next year, the very same instrument, presented by Battocchi was awarded the silver medal of the Institute of Sciences, Letters and Arts of Venice.
} 


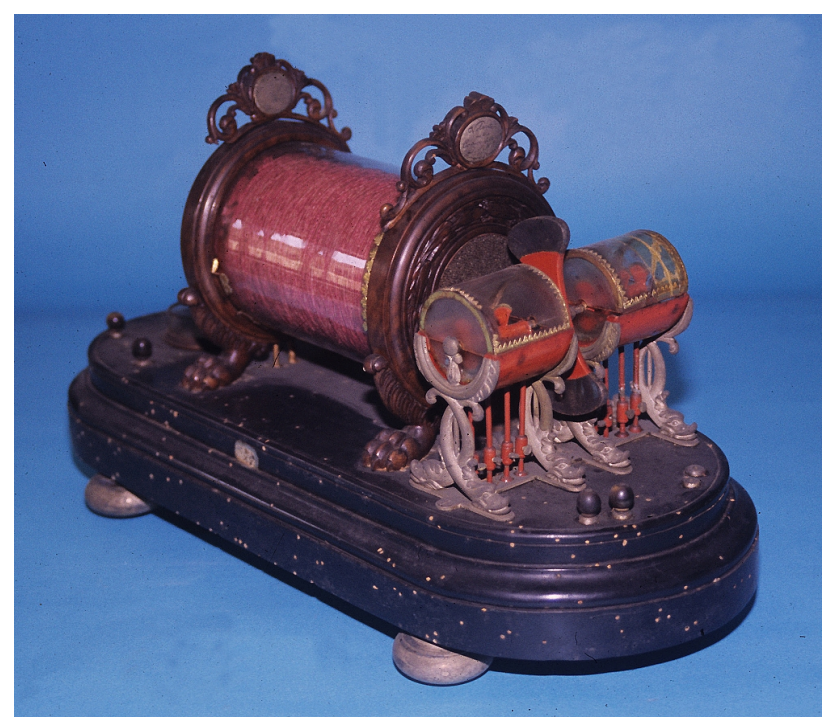

Figure 2. The induction coil designed by Vincenzo Vignola and bearing the trademark's label of the Verona-based manufacturer Giovanni Battista Battocchi. By courtesy of Physics Museum “Antonio Maria Traversi” in Venice.

Agriculture, Arts and Commerce ${ }^{13}$ of Verona, led, a year later, the same Academy to request that a scientific dissertation be written, containing an accurate description of the improvements brought to the Callan machine. The memoir was indeed presented during the academic session of March 4, 1852 and it was read by Paolo Vignola (1817-1897), member of the Academy and Vincenzo’s brother, a physicist himself. The initial interest for Callan's device was actually due to Paolo, as well as the initiative to involve his brother in the study of the necessary changes. The story was recounted in 1857 by the President of the Academy, Dr. Giulio Camuzzoni, in a historic speech:

Abbot Paolo Vignola, an Academy member, gave us a detailed and scientifically accurate description of the changes introduced by his brother, Abbot Vincenzo, to the Callan induction electromotor, which changes merited the author the Academy's $2^{\text {nd }}$ class gold medal, in 1851 [....]. With good reason the gold medal was awarded to Abbot Vincenzo, and with good reason the judges decreed that Abbot Paolo's memoir, describing the improvements rewarded by said medal, be published in the Academy's Journal (Camuzzoni, 1857: pp. 53-54).

The manuscript of this memoir, which was in fact never published, was recently found in the Academy’s archive (Vignola, ms., undated) ${ }^{14}$. The reasons why it was never published remain unknown, but what it is certain is that, perhaps in order to repair to that shortcoming, the Academic Board decided, in its session of July 20, 1854, to appoint Abbot Vincenzo corresponding member ${ }^{15}$ of the Verona Academy of Agriculture, Arts and Commerce. The same failure to publish the paper determined Father Giuseppe Pederzolli ${ }^{16}$, " $a$ fellow disciple and now a close

\footnotetext{
${ }^{13}$ It currently bears the name Accademia di Agricoltura, Scienze e Lettereof Verona; hereinafter referred to as AASLVR.

${ }^{14}$ AASLVR, Fund Manuscripts, B.I.16. The memoir, signed by Paolo Vignola, includes 24 handwritten pages with various illustrations. Its title is "Sopra alcune modificazioni e miglioramenti introdotti nell'elettromotore per induzione di Callan" ["On a series of changes and improvements made to Callan's induction electromotor"].

${ }^{15}$ The relevant nomination diploma, dated July 2, 1854 and signed by Angelo Messedaglia, is preserved at the General Archives of the Stigmatines of Verona, Envelope 33.

${ }^{16}$ Giuseppe Pederzolli (Riva 1820-Rovereto 1893) was educated at the Collegio Mazza of Verona, and then at the seminary high school of Trento. Ordained priest in July 1844, he was a preceptor, upon Rosmini's recommendation, in the Fedrigotti house in the town of Sacco and, in 1849, he became a supply teacher at the Rovereto Secondary School. In order to improve his knowledge of physics and philosophy, he first enrolled in the courses of the Innsbruck University, secondly, in Vienna University (1857). In 1859-60 he taught in Trento, and then he became a permanent professor of physics, mathematics and introduction to philosophy at Rovereto Secondary School, of which he became headmaster in 1887. From 1889 until his death, he served as the director of the public library of Rovereto. Despite Trento diocese's ban, he was a fervent supporter of Antonio Rosmini and faced, with dignity, the public censure by the Bishop of Trento, Mons. Valussi, for one of his works on Rosmini’s “forty propositions”. From 1852 he was also a member of the I. R. Accademia degli Agiati and secretary of the Rovereto Agrarian Academy.
} 
friend", as he wrote, of Vincenzo Vignola, to take the initiative in 1856 of making public "for the first time and with the consent of Vignola" the story of the electromotor and of its changes. In the opening of his paper, Pederzolli clarifies his motivations:

Five years ago, Abbot Vincenzo Vignola of Verona brought vital improvements to the magneto-electric induction device invented by Mr. Callan. The Academy of Agriculture, Arts and Commerce of that city recognized the entire importance of these improvements in April 1851, and, as a token of amply deserved appreciation, awarded his illustrious fellow citizen with the gold medal, $2^{\text {nd }}$ class. This is undoubtedly a new step in the progress of science; and, since no one has yet rendered this progress public, I take great joy in bringing a modest, but a solemn tribute of respect, affection and homage to the noble endeavor of the most distinguished Abbot [...] (Pederzolli, 1856: p. 3).

The memoir manuscript, as well as Pederzolli's subsequent contribution allowed us to reconstruct this episode with sufficient clarity and, at the same time, provided us with precious information concerning the impact that the introduction of the induction coil had on the Italian scientific community, in the early 1840s.

\section{Paolo Vignola's Unpublished Manuscript}

Paolo begins his manuscript by stating that as soon as he was called upon by his bishop to teach physics at the Episcopal seminary in Verona, he became aware of the scarcity of scientific instruments at his disposal and set out to establish a Physics Cabinet which would allow him to properly teach experimental physics. His chief concern was to get hold of a powerful induction electromotor that would allow him to demonstrate chemical and physiological effects of a certain magnitude ${ }^{17}$. The opportunity and the idea came when Paolo was shown the new model of Dell'Acqua's coil (see Figure 1) by a fellow member of the Verona Academy of Agriculture, Arts and Commerce, Mr. Gaetano Spandri ${ }^{18}$. When the machine was activated, Paolo's interest was immediately spurred and he decided to have a similar one built. With this in mind, he then asked for the help of his brother Vincenzo, a physicist and mechanic expert himself. After having built one, Vincenzo set out to make various changes so as to improve the effects and the overall effectiveness of the device. The found manuscript contains meticulously detailed drawings and descriptions both for Spandri's coil and for the changes that were made from time to time, in subsequent phases, to the original device. The first change consisted in changing the current's direction of the primary winding at each opening or closing of the circuit, in other words, to produce an oscillating current. The reason was that a current always running in the same direction could generate over time a residual magnetism of the soft iron wire bundle inside the instrument, thus slowing down the cyclic demagnetization times of the bundle. In order to implement this change, Vincenzo Vignola had to design a new interrupter consisting of a wooden box vessel with four ring-shaped concentric compartments, which were filled with mercury, on top of which a magneto-flywheel with four metal tips would rotate horizontally; the flywheel consisted of a permanent magnet under which two pairs of copper pointed wires were fixed on the longitude ${ }^{19}$ (see Figure 3). With this new device, some electrophysiology experiments conducted years earlier by Francesco Zantedeschi (1797-1873) on two pigeons were repeated, yielding “much more remarkable” results (Zantedeschi, part II, 1845: pp. 432-433). Once he had obtained the reversal of the current in the primary winding and more sizeable sparks, Vincenzo's next efforts were aimed at obtaining even more rapid interruptions of the current. For the latter purpose, the interrupter's vessel was modified once more in order to increase breaks of the current in the primary winding. This second modification consisted in dividing the vessel into four circular sectors and in reducing the mobile magneto-flywheel to a new cruciform system with four metal tips. The latter was in fact composed of two small permanent magnets set in a cross; under each polar extremity there were two pairs of parallel copper pointed wires, so that each tip would connect the opposite polarities of the two magnets (see Figure 4). This layout meant that at every turn of the

\footnotetext{
${ }^{17}$ This is the exact statement reported by Vignola in his manuscript: I was yearning to possess, among others, an induction electromotor that would allow me to demonstrate how, by using a hydroelectric current successively and rapidly interrupted, one may obtain a series of induced and re-conducted currents strong enough not only to be indicated by the galvanometers, but also to generate chemical and physiological effects of a certain value (AASLVR, Fund Manuscripts, B.I.16, folia 1r).

${ }^{18}$ Spandri (1796-1859), was a Verona-born astronomer, meteorologist, naturalist, agronomist and, in the words of the Italian physicist Zantedeschi, "a zealous cultivator of the physical sciences".

${ }^{19}$ In this respect, Paolo writes: After much thought, my brother managed to obtain the reversal of the poles in the bundle of iron wires by means of a newly constructed vessel and of a flywheel with a permanent magnet; being equipped with all the necessary appendixes [radial extensions] and owing to its circular movement, this flywheel is beautifully effective in reversing the core polarity during the breaking and making of the primary current (AASLVR, Fund Manuscripts, B.I.16, folia 6r).
} 


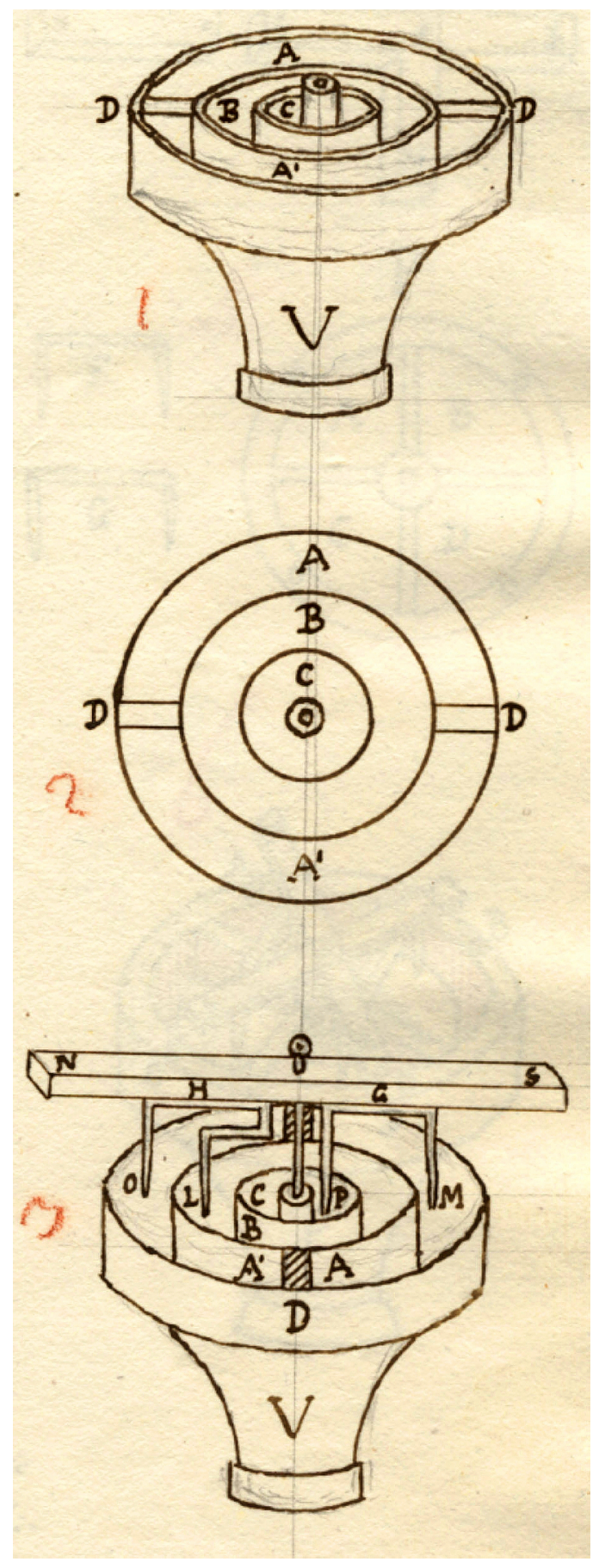

Figure 3. The original drawing of the first interrupter as modified by Vincenzo Vignola, found in Paolo Vignola's manuscript memoir. By courtesy of "Accademia di Agricoltura, Scienze e Lettere” in Verona.

magneto-flywheel, at least four sparks were generated from the contact of the copper tips with the convex menisci of the mercury present in the four vessels. The subsequent changes (at the end there will be five in all) aimed at fixing certain malfunctions of the device. Without going into details, there were essentially two main defects with the instrument: the spillage of the mercury over the vessel's rim, because of the vortex created by the rotation of the flywheel, and the lack from the secondary winding of high voltage pulses flowing in the same direction. 


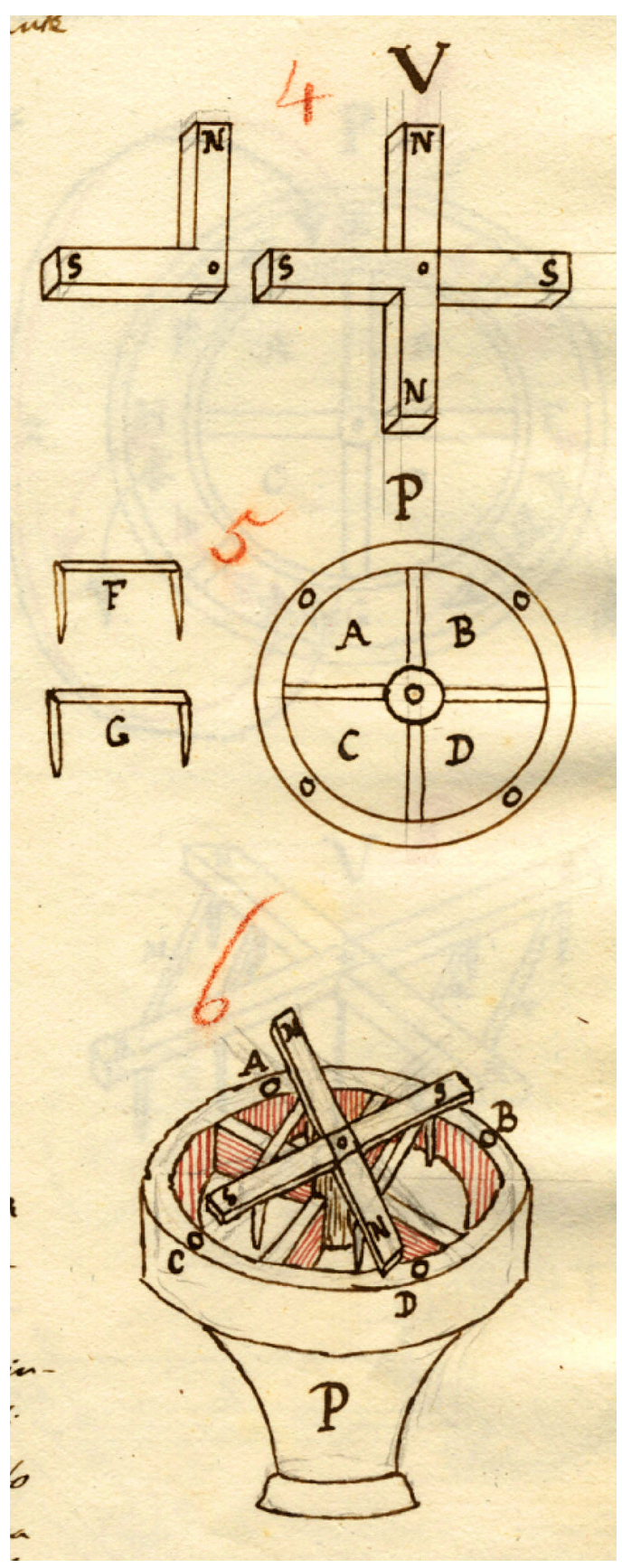

Figure 4. The original drawing of the second interrupter as modified by Vincenzo Vignola, found in Paolo Vignola's manuscript memoir. By courtesy of "Accademia di Agricoltura, Scienze e Lettere" in Verona.

Vincenzo solved these problems gradually. First, he took on the problem of the weak and brief contact between the tips connected to the flywheel and the mercury menisci, a defect that was amplified by the continuous dispersion of the mercury produced by the speed of the movement of the copper tips flowing through it; in order to fix that, Vincenzo designed a new vessel with four compartments in which an equal number of metal contacts (two in shaped disks and two in sharp fins) came into electrical contact with the mercury in which they sank; the sharp fins, in particular, as they rotated perpendicularly to the surface of the mercury and only sank in for half a spin, did not 
generate any spillage of the liquid from the vessel when they re-emerged. Moreover, the vessel also acted as an automatic commutator to reverse the primary current polarity, as it utilized an ingenious exchange of electrical contacts at the moment of the current's break. The problem remained, however, of rendering automatic the reversal of the current in the secondary winding also. To solve the latter problem, Vignola introduced a second vessel, perfectly similar to the first one, which made it possible by means of a contacts exchange, for the direction of the secondary current pulses to be automatically switched at every interruption in the primary circuit. The final result of all these changes was the construction by Vignola of a new and more complex automatic system to break and reverse currents; it was equipped with two vessels and a long rotating metal flywheel whose electric contacts, moving no more horizontally, but vertically, interacted with a pair of wooden box vessels, each divided into four compartments filled with mercury (see the entire system, as constructed by Battocchi in Figure 2 and the original hand drawing by Vignola in Figure 5). The flywheel, placed on top of the vessels, consisted of a long horizontal axis on which a central permanent vertical magnet and a few lateral metal fins and disks were fixed in a radial layout (see Figure 6). The revolving magnet was positioned in front of the iron core of the primary coil consisting of a bundle of soft iron rods while the metal fins and the disks were able to dip into the mercury that filled the various compartments, while rotating. Thanks to this particular layout, the flywheel was set in continuous spinning by the forces of attraction and repulsion created between the poles of the permanent magnet and the oscillating pole of the electromagnet core of the primary coil.

\section{Conclusions}

The Vignola's induction coil being preserved at the “Antonio Maria Traversi” Physics Museum of Venice bears an important testimony to the intellectual vivacity with which the physicists and manufacturers of the mid-nineteenth century operated in pre-unification Italy. The device also, before the final achievement of the famous

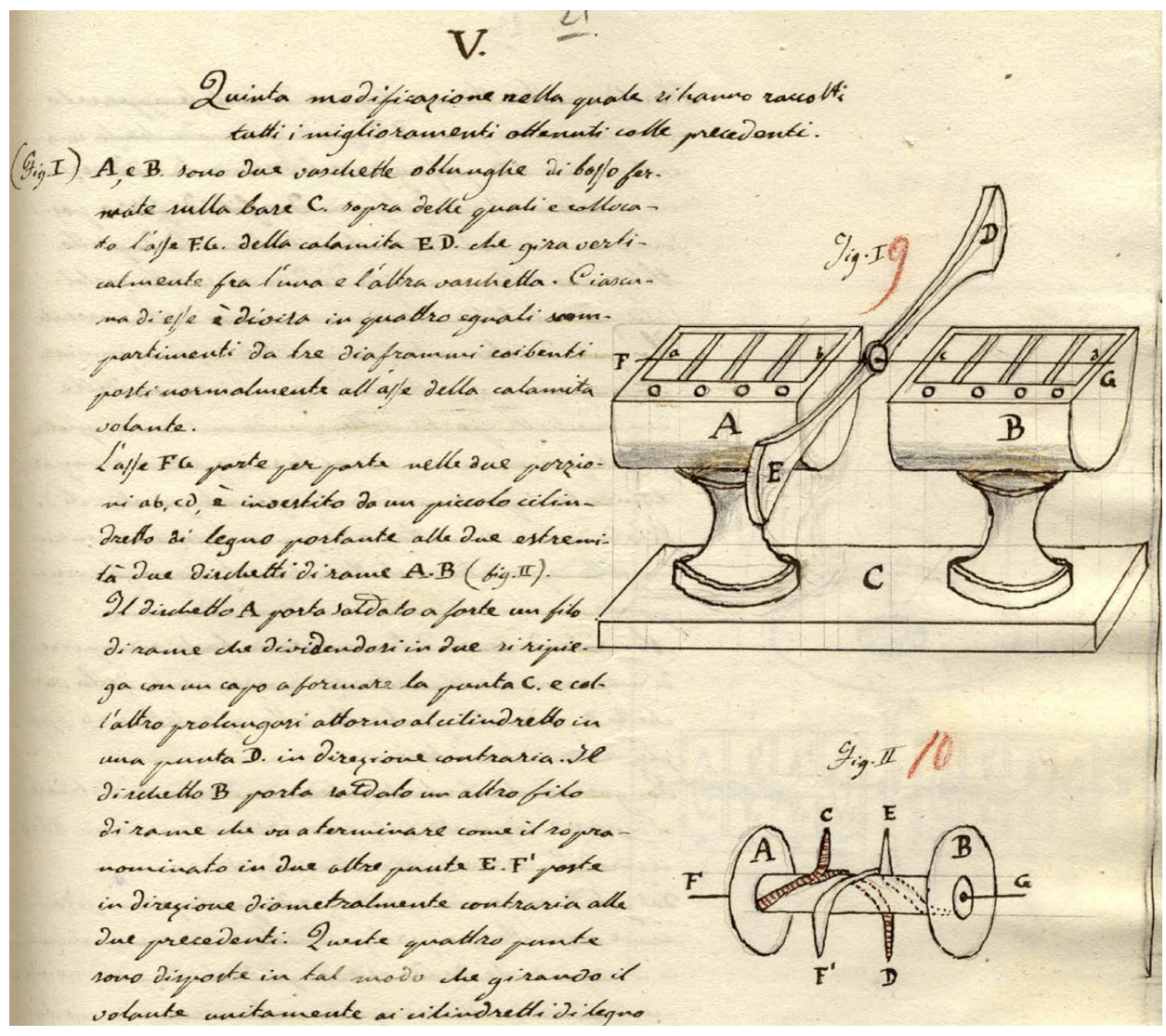

Figure 5. The original drawing of the last commutator-interrupter as modified by Vincenzo Vignola and found in Paolo Vignola’s manuscript memoir. By courtesy of “Accademia di Agricoltura, Scienze e Lettere" in Verona. 


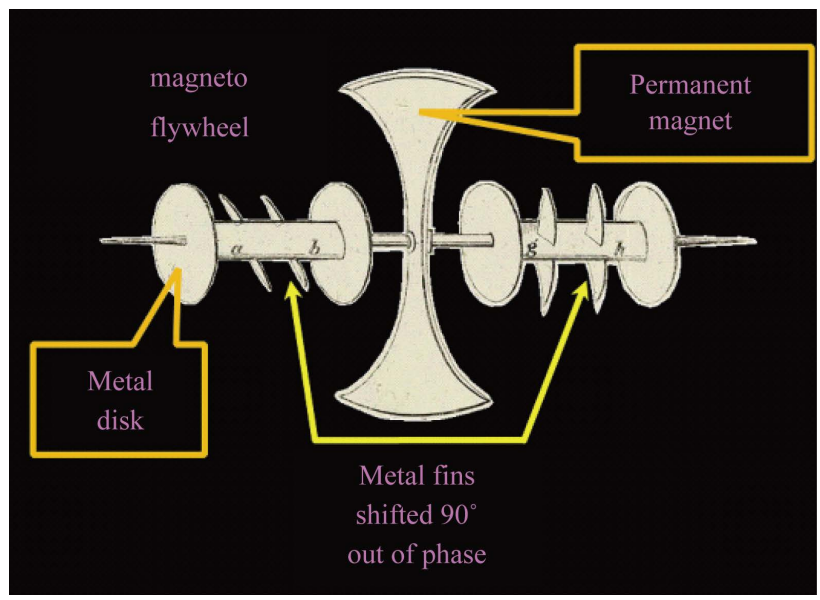

Figure 6. Structure of the magneto flywheel. The fins and disks are connected to each other by means of metal rods inserted into the flywheel's horizontal axis.

Ruhmkorff model, represents an almost unique example of an induction machine provided with a number of very original functional features. In particular, the presence both in the primary and secondary windings of a special vessel acting in both circuits as a commutator-interrupter system, has no correspondent, to the best of our knowledge, in any other device from that time. For a clearer explanation of the functioning principle of the device, let us revisit synthetically how each vessel works when the current flows through the primary and secondary coil. As concerns the vessel of the primary winding, it happens that, for each half turn of the metal fins, the current breaks and reverses its direction along the entire primary winding; at the same time, the soft iron wire core inside the primary winding rapidly takes an intermittent magnetization, reversing its magnetic polarity at every half turn. On the other hand, as concerns the function of the vessel mounted in the secondary winding, it breaks and reverses the induced secondary currents which, note well, are shifted $90^{\circ}$ out of phase compared to those in the primary coil. Based on these uncommon characteristics, this vessel of the secondary essentially carried out, de facto, the typical function of a current rectifier. However, while this ingenious device showed intriguing features, it could not compete with the solutions that Ruhmkorff was starting to adopt around the same period for the construction of his own induction coil. In fact, the German instrument maker provided the primary circuit of his apparatus with a more efficient electromagnetic interrupter, an automatic vibrating spring named Neeff's or Wagner's hammer break, which guaranteed much faster current breaks ${ }^{20}$. Moreover, he also equipped the base of his induction coil with the Fizeau condenser which, interposed in the primary circuit, limited, on the interrupter contact points, sparking and metal wear damages caused by the extra-currents; at the same time, this solution greatly amplified the secondary's electromotive force, increasing the intensity of the induced currents and the spark-length. Battocchi himself, who was a highly competent instrument maker, initially adopted the pattern and the mechanical solutions designed by Vignola, but a few years later, he changed his mind and chose to build and sell his induction coils ${ }^{21}$ on the basis of Ruhmkorff's new model. From a historical point of view, despite its limited success, the model proposed by Vignola represents a significant chapter on the impact of the induction coil's introduction in Italy. While studying the device, one is chiefly struck by a couple of technical solutions that were no doubt very original for that time and age. The first one consisted of the automatic reversing-switch of the direction of the current in the primary coil at each circuit breaking and making; a similar solution was partially proposed, in a manual form, only by Ruhmkorff himself, who, in order to cut off or reverse the direction of the primary current, added on the basis of the instrument a "current reverser"22 (which was later known as the Ruhmkorff's reverser). A second relevant and unusual technical solution concerned the presence in

\footnotetext{
${ }^{20}$ This type of circuit-breaker, made in 1839, became an important improvement of the induction coil and was in use until the beginning of XX century.

${ }^{21}$ In 1858, Battocchi presented in an Agriculture and Industrial Awards, granted by the Venetian Institute of Science, Letters and Arts, an "induction machineà la Rumkorf [sic]" which received the silver medal. A model of this type, signed and dated "Battocchi G. B. Verona 1865", is now preserved at the Physics Cabinet of the "Scipione Maffei” High School of Verona.

${ }^{22}$ This manual switch or key was activated by means of a handgrip. It was composed of a turning ebonite cylinder having on each side a brass plate pressed by two vertical sliding elastic brass springs joined to the ends of the primary wire.
} 
the secondary winding of a second vessel that, as previously discussed, acted as self-reversing electromagnetic switch on the induced currents, changing also their phases. These changes provided the metal poles of the spark gap of the instrument with unidirectional discharges, instead of bidirectional ones. This mechanical solution, although suitable for other experiments of the time ${ }^{23}$, was never developed further and, as far as we know, it was not adopted on any other type of induction coil. In relation to this point, perhaps, the author's intention was to make the instrument appropriate for a larger number of experiments, allowing, at the same time, the observation of more considerable effects. Let us not forget that, during that time, the most widespread and popular devices were the Clarke magneto-electric machines, which could develop both oscillating and unidirectional currents. Such magneto-electric generators allowed for a great variety of experiments to be conducted and for many visual effects to be obtained, especially with unidirectional charges; these effects could be physiological, chemical, optical, thermal, magnetic and electro-dynamic in nature. By the latter perspective, the opportunity to have a more powerful instrument performing similar operating functions could be, for that time, very exciting, if we try to immerge ourselves in the dominant and peculiar research context of those years related to the Physics of Visibility or of Observables (D'Agostino, 2005). Indeed, after the discovery of electromagnetic induction, the theoretical debate of the time was centered on the nature of the electric currents, which could be generated in rather diverse manners. The experimental methodology in use was to patiently describe all the observed phenomena and then classify them in order to outline potential correlations ${ }^{24}$. On this operational basis, a correlation was made between different kinds of electricity, in terms of identity of the observed effects. In this context, the efforts made by Vignola brothers, to modify the induction coil so as to render it more effective and obtain stronger effects, were quite logical, as they reflected the experimental methodology adopted by the physicists of the time and age: they conducted their experiments in a way that privileged the amplification of the phenomena to the detriment of their measurements ${ }^{25}$.

\section{References}

Callan, N. (1836). A Description of an Electro-Magnetic Repeater, or of a Machine by Which the Connexion between the Voltaic Battery and the Helix of an Electro-Magnet May Be Broken and Renewed Several Thousand Times in the Space of one Minute. The Annals of Electricity, Magnetism, and Chemistry, 1, 229-230.

Camuzzoni, G. (1857). Storia dell’Accademia d’Agricoltura Arti e Commercio in Verona relativa al Triennio 1851-52-53 letta dal socio Presidente Dr. Giulio Camuzzoni chiudendosi la Provinciale Esposizione il giorno 15 gennaio 1857. In Memorie dell'Accademia d'Agricoltura Commercio ed Arti di Verona (Vol. XXXIV). Verona: Stabilimento tipograficoVicentini e Franchini.

D’Agostino, S. (1986). Leopoldo Nobili e la Fisica degli Osservabili. In G. Tarozzi (Ed.), Leopoldo Nobili e la Cultura Scientifica del Suo Tempo (pp. 97-103). Bologna: Nuova Alfa Editoriale.

D’Agostino, S. (2005). Gli Strumenti Scientifici e la Scienza. Manduria: Barbieri Editore.

Faraday, M. (1833). Experimental Researches in Electricity (Third Series, § 7). Identity of Electricities Derived from Different Sources. Philosophical Transactions of the Royal Society of London, 123, 23-54.

Fleming, J. A. (1892). Chapter 1: The Historical Development of the Induction Coil and Transformer. In The Alternate Current Transformer in Theory and Practice (Vol. II, pp. 1-118). London: The Electrician Printing and Publishing Company Limited.

Greenslade Jr., T. B. (2013). Charles Grafton Page and His Shocking Coil. eRittenhouse, 24, No. 1, Issue 71. http://www.erittenhouse.org/artitcles/erittenhouse-vol-24-1-2012-2013/c-g-page-and-his-shocking-coil/

Gurisatti, P. (1916). Brevi Cenni Biografici dei Padri Pietro Vignola, Vincenzo Vignola e Giuseppe Marchesini della Congregazione dei Preti delle Stimate di N.S.G.C. Verona: Tipografia Antonio Gurisatti.

Hackmann, W. D. (1989). The Induction Coil in Medicine and Physics, 1835-1877. In C. Blondel, F. Parot, A. Turner, \& M. Williams (Eds.), Studies in the History of Scientific Instruments (pp. 235-250). London: Rogers Turner Books LTD.

Hackmann, W. D. (1998). Induction Coil. In R. Bud, \& D. J. Warner (Eds.), Instruments of Science: An Historical Encyclopedia (pp. 328-330). London: Science Museum \& Garland Publishing, Inc., Washington: The National Museum of Amer-

\footnotetext{
${ }^{23}$ For instance, using a voltameter to carry out the electrolysis of water.

${ }^{24} \mathrm{As}$ is well known, it was Faraday, who in 1833, following his research in electro-chemistry, first pointed out the correlation between the various kinds of electricity generated from different sources (Faraday, 1833). However, in the opinion of Faraday, "correlation” and "identity" were not synonymous.

${ }^{25}$ On this point, D'Agostino correctly noted that, in the Physics of Observables, it is impossible to conduct measurements if the sensitivity of the instruments is pushed to the extreme. Indeed, such a practice will always be detrimental to the reproducibility and the precision of the measurements (D’Agostino, 1986, pp. 98-99).
} 
ican History, Smithsonian Institution.

Majocchi, G. (1850-1853). Elementi di Fisica ad uso dei Collegi Nazionali e dei Liceipel Corso Filosofico di Gianalessandro Majocchi (Two volumes). Torino: Cugini Pomba e Comp. Editori.

Page, C. G. (1867). History of Induction: The American Claim to the Induction Coil and Its Electrostatic Developments. Washington: Intelligencer Printing House.

Payen, J. (1965). Les Origines de la Bobine d’Induction. Revue d'histoire des sciences et de leurs applications, 18, 315-318. http://dx.doi.org/10.3406/rhs.1965.2432

Pederzolli, G. (1856). Apparato d'induzione elettro-magneto-elettrica di Callan modificato dall'abate Vincenzo Vignola da Verona (pp. 3-26). Trento (Publisher Missing).

Post, R. C. (1976). Physics, Patents, and Politics: Biography of Charles Grafton Page. New York: Science History Publications.

Rowbottom, M., \& Susskind, C. (1984). Electricity and Medicine. History of Their Interaction. San Francisco, CA: San Francisco Press, Inc.

Shiers, G. (1971). The Induction Coil. Scientific American, 224, 80-87. http://dx.doi.org/10.1038/scientificamerican0571-80

Vignola, P. (manuscript, undated). Sopra Alcune Modificazioni e Miglioramenti introdotti nell'Elettromotore per Induzione di Callan. Fund Manuscripts of the Accademia di Agricoltura, Scienze e Lettere of Verona, B.I.16, folios 1-24.

Zambra, B. (1852). Primo Programma dell'I.R. Ginnasio liceale di Venezia. Pubblicato alla fine dell’Anno Scolastico 1851-52. http://liceo.convittofoscarini.it/storia/aument52.htm

Zantedeschi, F. (1844-1845). Trattato del Magnetismo e della Elettricità dell'Ab. Zantedeschi (Parte I \& II). Venezia: dalla Tipografia Armena di S. Lazzaro. 